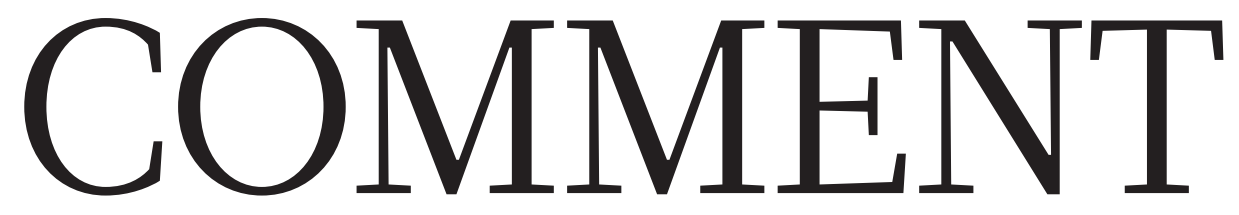

EMISSIONS Boycott goods from states that top dirty-energy league $\mathbf{p . 2 9 4}$

ECoNomics Why innovation should be counted as a good national investment $\mathbf{p . 2 9 7}$

\section{TECHNOLOGY Pioneer of}

virtual reality reflects on the wild ride so far $\mathbf{p . 2 9 8}$
DISASTERS More education and research needed to fight future fires $\mathbf{p . 3 0 0}$

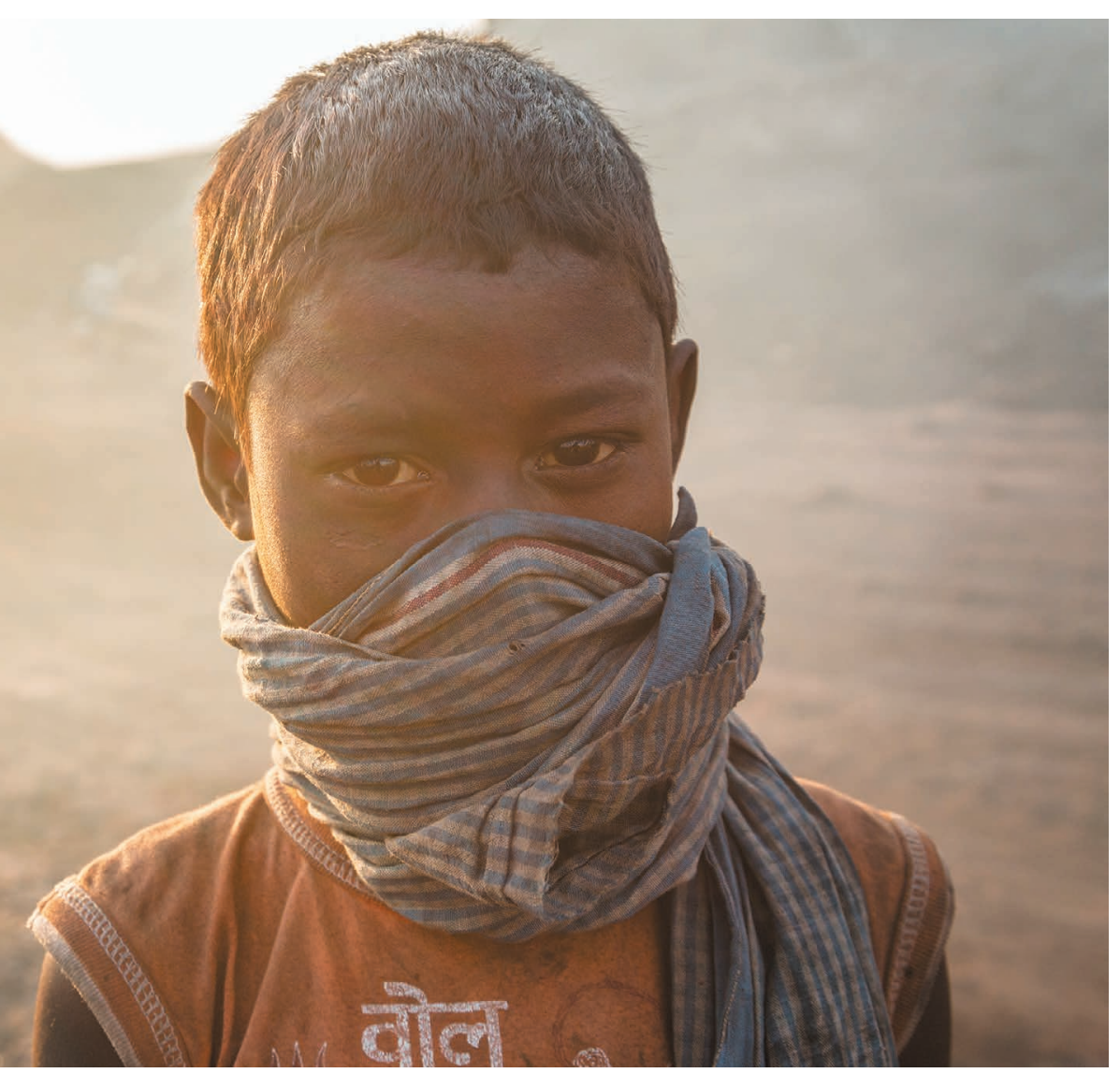

A child in Jharkhand, eastern India, breathes air that is heavily polluted by smoke spewing from underground coal-mine fires.

\title{
Chemists can help to solve the air-pollution health crisis
}

Learning more about how pollutants enter and damage the body would reduce disease and deaths, say Jos Lelieveld and Ulrich Pöschl.

$\mathrm{P}$ oor air quality is one of the leading five health risks worldwide, along with high blood pressure, tobacco smoking, diabetes and being overweight ${ }^{1,2}$. In 2015 , it contributed to nearly $8 \%$ of all deaths worldwide $^{2}$. Long-term exposure to polluted air has been linked to respiratory infections, chronic obstructive pulmonary disease, stroke, heart attack and lung cancer. It is justifiably called 'passive outdoor smoking'.

Air pollutants such as nitrogen oxides ( $\mathrm{NO}$ and $\mathrm{NO}_{2}$, together called $\mathrm{NO}_{\mathrm{x}}$ ), ozone $\left(\mathrm{O}_{3}\right)$ and particulates must be controlled in cities and other polluted regions ${ }^{3,4}$. Fine particulate matter with a diameter of less than 2.5 micrometres $\left(\mathrm{PM}_{2.5}\right)$ is the chief hazard because it is small enough to penetrate deep into human airways and lungs. More than $90 \%$ of the world's population - about 7 billion people - is exposed to outdoor pollution above the World Health Organization (WHO) guideline limit of 10 micrograms of $\mathrm{PM}_{2.5}$ per cubic metre averaged over a year.

Around 4.5 million people die each year from the effects of outdoor air pollution ${ }^{1,2}$, a figure corroborated last month by the Lancet Commission on Pollution and $>$ 
Health (go.nature.com/2zcqzau). Half of these are in China and India, although Russia has a higher per-capita death rate: about 1.6 inhabitants per thousand each year, twice as many as in India ${ }^{5}$. On average, each person affected dies 28 years earlier than they would do if they had breathed clean air, amounting to some 120 million years of human life lost each year ${ }^{5}$ (see 'Lost years').

Air-quality regulations in most countries fall short of preventing disease and mortality, and annual standards for $\mathrm{PM}_{2.5}$ often exceed the WHO guideline limit. In the European Union, the current limit of 25 micrograms per cubic metre $\left(\mu \mathrm{g} \mathrm{m}^{-3}\right)$ will be reduced to less than $20 \mu \mathrm{g} \mathrm{m}^{-3}$ in 2020 . Yet an estimated 274,000 deaths in the region are related to poor air quality. In Japan, the limit is $15 \mu \mathrm{g} \mathrm{m}^{-3}$ (79,000 related deaths) and in the United States, $12 \mu \mathrm{g} \mathrm{m}^{-3}(115,000 \text { related deaths })^{5}$. The 'safe threshold', or minimum-risk exposure level, was lowered in May after epidemiological studies ${ }^{2}$ indicated that it should be dropped from $5.8-8.8 \mu \mathrm{g} \mathrm{m}^{-3}$ to $2.4-5.9 \mu \mathrm{g} \mathrm{m}^{-3}$. This is well below the WHO limit.

Although public-health specialists have uncovered connections between air pollution, disease and mortality, further information is needed to disentangle the causes and effects. For example, the toxicities of different types of particulates, individually and in mixtures, are poorly known. Too few atmospheric chemists work directly on health impacts.

More extensive, multidisciplinary research teams are needed to optimize emissions-control measures for human health ${ }^{6}$. As well as medics and biologists, these should include epidemiologists, toxicologists, health economists and atmospheric chemists.

\section{FOGGY VIEW}

Air quality affects the lifespan of individuals. Atmospheric chemistry affects the lifespan of air pollutants. Linking these effects is far from straightforward, for several reasons.

First, outdoor air pollution has many sources. Residential heating and cooking, especially using fuel stoves and fires in lowincome countries, have the greatest impact on mortality. These explain roughly 1.35 million deaths per year. ${ }^{5}$. Agriculture has the next biggest impact, contributing to one-fifth of deaths ${ }^{4}$ - largely through ammonia released by manure and fertilizer use, which combines with sulfate and nitrate in the air to form ammonium sulfate and ammonium nitrate and thus $\mathrm{PM}_{2.5}$. Power generation, industry and traffic also contribute to ozone and $\mathrm{PM}_{2.5}$.

Second, atmospheric chemical reactions are complicated to follow. Ozone and most $\mathrm{PM}_{2.5}$ particles are secondary pollutants, formed from a host of anthropogenic and natural emissions. Environmental factors, such as temperature, humidity and dispersal by the wind, influence pollution levels. Fine particulates inhaled in one place will have been emitted upwind and could have been transported for days in the atmosphere, as well as undergoing chemical changes.

Third, pollutants interact with one another. Levels of ozone, for example, are determined by reactions involving $\mathrm{NO}_{x}$ and volatile organic compounds (VOCs) in sunlight. So a combination of measures is needed to reduce ozone. But the results can be hard to predict.
Even though the EU has reduced its emissions of $\mathrm{NO}_{\mathrm{x}}$ and VOCs by $2-3 \%$ per year since the early 2000s, ozone

"A global effort is needed to achieve unified air-quality standards." levels in the region have not fallen ${ }^{7}$. Emissions can be blown in from other continents. Mitigating $\mathrm{NO}_{\mathrm{x}}$ might have other benefits, however, such as slowing the formation of sulfate particles in Asian megacities ${ }^{8}$.

Fourth, emission levels are uncertain and often underestimated because they are based on a limited number of measurements and various assumptions. About one-third of diesel emissions from heavy-duty vehicles and those from more than half of light-duty vehicles breach certification limits globally 9 . Holding diesel vehicles to existing emissions standards, such as EURO 6/VI, would bring immediate health benefits.

Finally, there is a non-linear relationship between levels of air pollution and health impacts. Halving the amount of pollution does not necessarily halve the number of deaths. The most polluted places need the largest mitigation efforts, as China is finding out. For example, in polluted regions in eastern China, sulfur dioxide emissions have dropped by more than $50 \%$ since 2010 , but mortality rates have decreased only marginally $^{4,5}$. Benefits multiply as the air is cleaned, however. By our calculations, mortality rates from air pollution in the United Kingdom have fallen by $30 \%$ since it implemented $\mathrm{EU}$ air-quality legislation between the 1970 s and 2010. Yet the drop was less than $20 \%$ in more-polluted member states such as Germany and Italy, even though they applied the same regulations in their transportation and energy sectors ${ }^{10}$.

Emissions-control policies need to be tailored to local conditions and take the chemistry and global flows of air pollutants into account. Yet nations in Asia, the Middle East and Africa have not signed up to the United Nations Convention on Long-range Transboundary Air Pollution. In many countries, local authorities are responsible for air quality, even though they have little control over the atmospheric environment.

\section{UNCERTAIN TOXICITY}

Too little is known about how different components contribute to the overall toxicity of particulate matter. Such information could inform policy strategies to reduce deaths for example, by rapidly setting severe limits for the most dangerous compounds. Transition metals, including iron and copper, produce reactive oxygen species that stress the body. Soot and other carbonaceous compounds can be accompanied by polycyclic aromatic hydrocarbons that are mutagenic and carcinogenic. Ultrafine particles (less than $0.1 \mu \mathrm{m}$ in diameter) can penetrate the lung membranes and enter the bloodstream.

There is a correlation in the ambient concentrations of $\mathrm{PM}_{2.5}$ constituents that are emitted from the same source. Atmospheric scientists can help by attributing the constituents to their sources. Chemists can elucidate the molecular mechanisms by which pollutants interact with the body and immune system. Experimental and theoretical methods for investigating

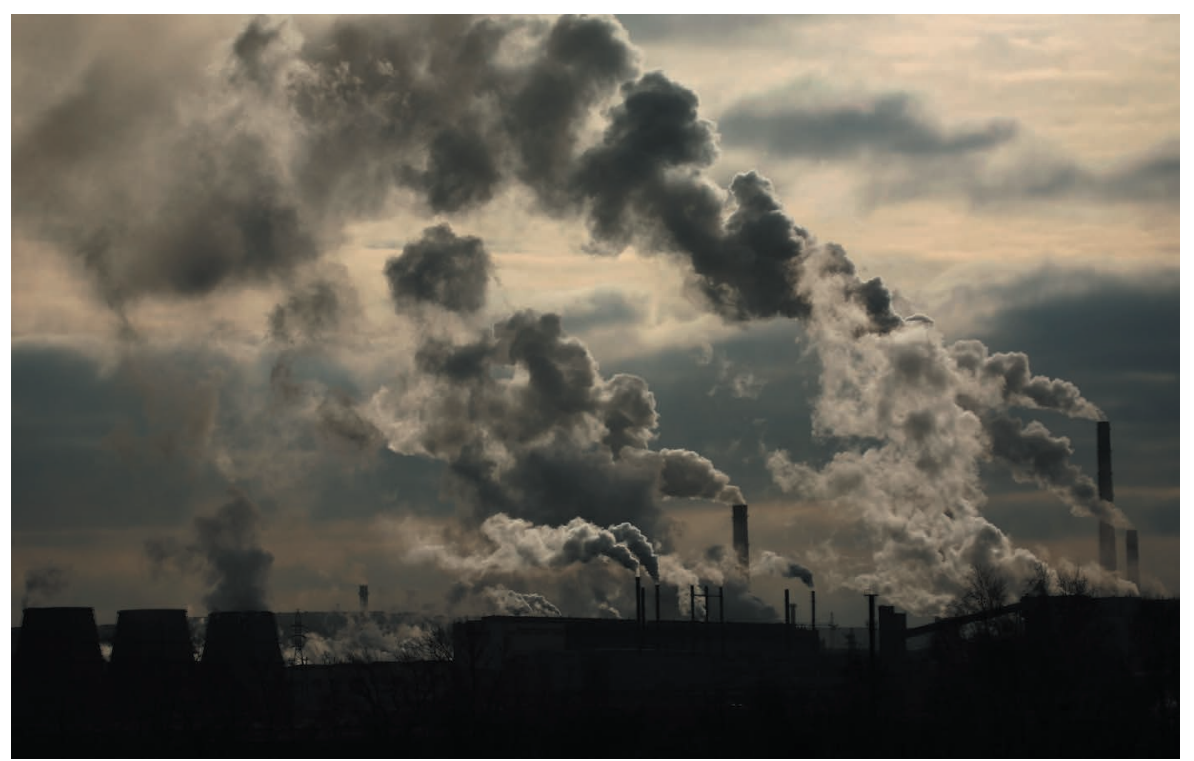

Factories in Chelyabinsk, Russia - a country with a high per-capita death rate from outdoor air pollution. 


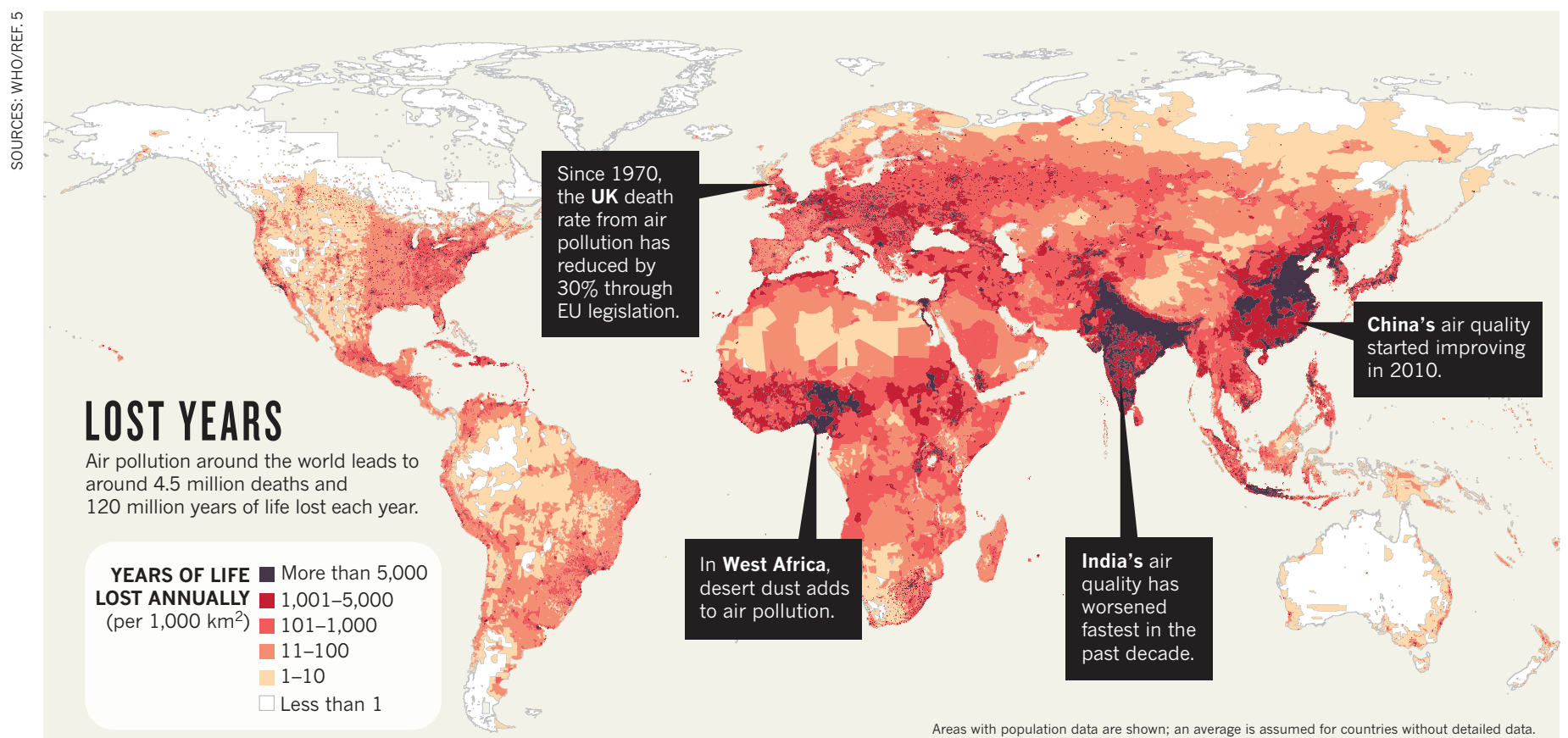

atmospheric processes could be extended to follow the interactions of air pollutants with the skin and with fluids that line airways. Exposures and responses should be related by combining such studies with physicalchemistry experiments and simulations, as well as with biomedical ones.

Studies of densely populated and highly polluted locations - 'supersites' of atmospheric and health research, such as major Chinese cities - are a promising way to test hypotheses about toxicity and resolve the interplay of different pollutants. Techniques for detecting highly reactive and short-lived hazardous compounds, such as carboncentred and oxygen-centred organic radicals, could be combined with toxicological experiments ${ }^{6}$. These might include exposing cell cultures to ambient air, or epidemiological investigations of respiratory, cardiovascular and inflammatory diseases.

Investigations at multiple locations - which have varying chemical and meteorological conditions and different origins of pollution - can build on information from air-quality networks to help resolve the health impacts of various pollution sources. Such studies could untangle the role of diesel exhaust particles, of wear and tear on vehicle tyres and brakes, or of secondary organic aerosols. They might reveal the relative importance of the mass of $\mathrm{PM}_{2.5}$ constituents versus particle size, number and composition.

The effects of inhaling reactive gases and oxidants, such as ozone and $\mathrm{NO}_{\mathrm{x}}$, and their influence on the surface properties and toxicity of fine particles should be explored. The interplay of aerosol particle and gas-phase components - including coagulation, adsorption and chemical reactions - could be important for understanding the growing prevalence of allergic diseases, which have increased markedly in Western countries ${ }^{11}$.

\section{BASIC RIGHT}

Each day, the average human inhales more than 10,000 litres of air and drinks about 2 litres of water. These needs must be enshrined in policies as human rights - each year, 4.5 million people die from polluted air and 1.8 million from polluted water ${ }^{1}$. A UN sustainable development goal states that access to safe water and sanitation is a human right. We think that there should also be a sustainable goal for clean air.

A global effort is needed to achieve adequate and unified air-quality standards. It should prevent highly polluting industries from relocating to countries that have more permissive environmental regulations, which leads to transboundary health impacts through international trade $\mathrm{e}^{12}$. Together with the WHO, the UN Environment Programme can bring together scientists and policymakers, as it has done for stratospheric ozone depletion and climate change. The World Bank, for instance, could more energetically support projects to control air pollution.

Atmospheric chemists should engage more actively in public-health research. They can develop affordable methods of measuring pollutants that represent human exposure and focus more on data-scarce regions in Asia, Africa, the Middle East and South America. They should apportion sources of $\mathrm{PM}_{2.5}$ and investigate the chemical interactions at the atmosphere-biosphere interface ${ }^{6}$. Targeting climate pollutants at the same time would be a win-win for climate-change mitigation and air quality - for example, by supporting the initiatives of the Climate and Clean Air Coalition (www.ccacoalition.org/en). The Pontifical Academy of Sciences also advocated this month for a reduction in air pollution (go.nature.com/2higlim).

Two international meetings in China this week could pave the way for the interdisciplinary collaborations that are needed: a symposium in Guangzhou on regional airquality management (16-19 November) and a conference on environmental pollution and human health in Chengdu on 17-19 November.

Jos Lelieveld is director of atmospheric chemistry at the Max Planck Institute for Chemistry in Mainz, Germany; and institute professor at the Cyprus Institute, Nicosia, Cyprus. Ulrich Pöschl is director of multiphase chemistry at the Max Planck Institute for Chemistry in Mainz, Germany. e-mail:jos.lelieveld@mpic.de

1. Global Burden of Disease Study 2015 - Risk Factors Collaborators. Lancet 388, 1659-1724 (2016).

2. Cohen, A. J. et al. Lancet 389, 1907-1918 (2017).

3. Thurston, G. D. et al. Eur. Respir. J. 49, 1600419 (2017).

4. Lelieveld, J., Evans, J. S., Fnais, M., Giannadaki, D. \& Pozzer, A. Nature 525, 367-371 (2015).

5. Lelieveld, J. Faraday Discuss. 200, 693-703 (2017).

6. West, J. J. et al. Environ. Sci. Technol. 50, 4895-4904 (2016)

7. Guerreiro, C. B. B., Foltescu, V. \& de Leeuw, F. Atmos. Environ. 98, 376-384 (2014).

8. Cheng, Y. et al. Sci. Adv. 2, e1601530 (2016).

9. Anenberg, S. C. et al., Nature 545, 467-471 (2017).

10.Crippa, M. et al. Atmos. Chem. Phys. 16, 3825-3841 (2016).

11. Reinmuth-Selzle, K. et al. Environ. Sci. Technol. 51, 4119-4141 (2017).

12.Zhang, Q. et al. Nature 543, 705-709 (2017). 